\title{
Modern Cartography - a Cross-disciplinary Science of Visualisation and Communication
}

\section{Ladies and Gentlemen, dear colleagues,}

it is a great pleasure for us to publish this special issue of KN Kartographische Nachrichten on the occasion of the $26^{\text {th }}$ International Cartographic Conference in Dresden hosted by the German Cartographic Society. In accordance with the conference president the DGfK Board, the editor, and the publishing house decided to dedicate this issue to the topic of "Cartography and Geographic Information Science in Germany, Austria and Switzerland". We give thanks to the authors of this issue for their willingness to contribute twelve articles representing the actual state of modern cartography in the German speaking countries.

Modern cartography is a cross-disciplinary science with a broad range of methods. In today's geographic information science community cartography is defined as science, business and art of visualisation and communication of spatio-temporal information. This definition reflects the high standards of quality in cartography concerning the visual representation of information. Furthermore, the increasing impact of alternative representations in 3D worlds, in acoustic or haptic maps and numerous other manners is highlighted as well as the expertise of cartography in respect of the distribution of spatio-temporal information in spatial data infrastructures. Geo-communication, in a broader sense, has finally found its way into professional education and academic studies and also into the practice of cartography.

With KN Kartographische Nachrichten the German Cartographic Society (DGFK) publishes a widely recognised journal of cartography and geographic information science. Established in 1951, it is the only cartographic journal in the Germanspeaking countries and among the oldest cartographic periodicals world-wide. In 1976, it has become the joint periodical publication of DGfK, the Cartographic Commission of the Austrian Geographical Society (ÖKK), and the Swiss Cartographic Society (SGK). Beyond that, KN Kartographische Nachrichten is intended to be a medium of internal and external information exchange on the national level and a representative of the German speaking countries in the international cartographic community. So far, the articles are predominantly in German (with English summaries); but increasingly papers in English are also published.

This special issue of KN particularly addresses to the participants of the 26 $6^{\text {th }}$ International Cartographic Conference 2013. This biannual world conference returns to Germany again, with ICA conferences having been held previously in Germany in Frankfurt in 1962 and Cologne in 1993. It is supposed to provide a forum for the presentation of scientific and application papers illustrating the efforts of the research community and the cutting-edge methods employed by mapping organisations. Meetings of the ICA Commissions and Working Groups will further international collaborative efforts to advance knowledge and techniques. Moreover, ICC 2013 provides the opportunity to visit technical and international map exhibitions and to meet socially with colleagues from the international Cartography and GI Science community.

Dresden boasts the highest density of art treasures as related to the area in Europe; and, for cartographers, the possibility to view one of the top international globe collections. Dresden is also the home of educational and research institutions that have progressed the theoretical and practical elements of Cartography and GI Science.

We look forward to welcoming the cartographers of the world in Dresden for the $26^{\text {th }}$ International Cartographic Conference in August 2013.

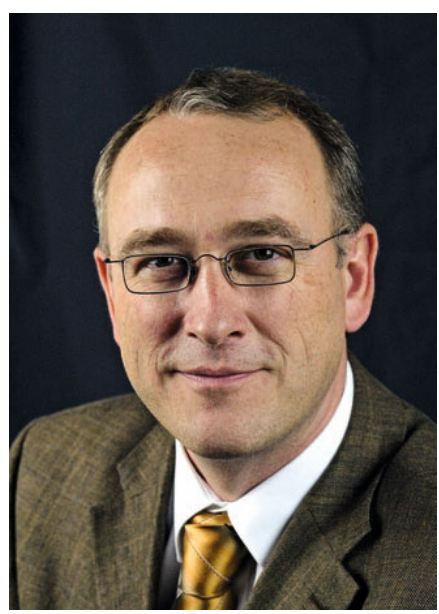

Prof. Dr. Manfred Weisensee President of the German Cartographic Society DGfK

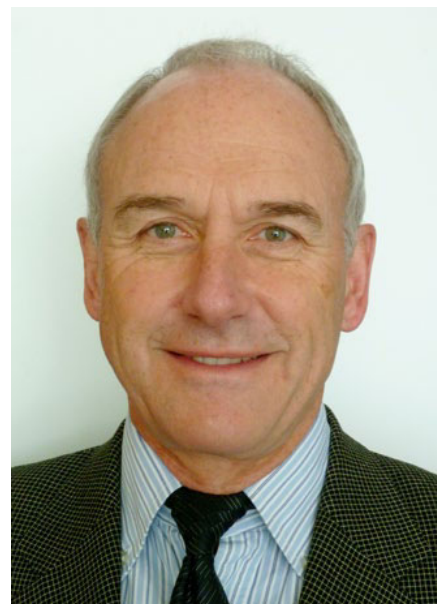

Prof. Dr. Manfred Buchroithner President of the 26th International Cartographic Conference 2013

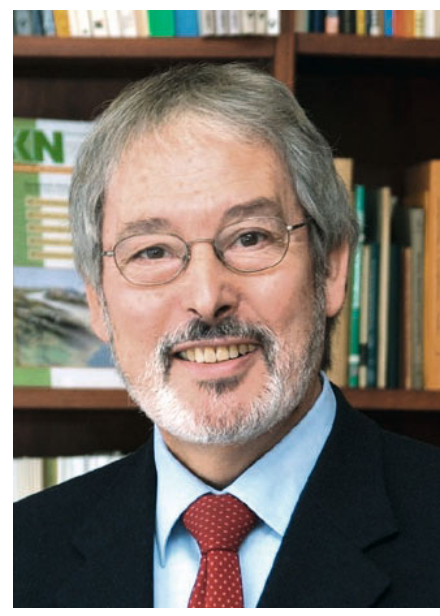

Dr. h.c. Rolf Harbeck Chief Editor of KN Kartographische Nachrichten 